\title{
FAT GRAFTING AFTER RADIOTHERAPY AND BREAST IMPLANT
}

Paulo Roberto Moura de Sousa ${ }^{1}$, Mauricio de Aquino Resende¹, Ailton Joioso', Raimundo Jovita Araujo Bonfim¹, Carlos Eduardo Witoslawski Breda'

${ }^{1}$ Amaral Carvalho Hospital - Jaú (SP), Brazil.

This is a case report of reconstruction of the right breast and aesthetic improvement of the left breast, in a 52-year-old smoker woman, with bilateral breast cancer, neoadjuvant chemotherapy, modified radical mastectomy on the right, quadrantectomy with left, lymphadenectomy, and radiotherapy (RT). She sought the Amaral Carvalho Hospital for reconstructive surgery after 6 years of treatment. She underwent fat grafting (FG) with $237 \mathrm{~mL}$ on the right breast and $90 \mathrm{~mL}$ on the left breast and correction of the left areola. After 6 months, a retromuscular tissue expander was placed on the right, and remodeling of the breast and correction of the surgical scar are done on the left. After 8 months of achieving expansion with $350 \mathrm{~mL}$ of saline solution, the tissue expander was replaced by a wide base anatomical prosthesis with $485 \mathrm{~mL}$ and a $225 \mathrm{~mL}$ nonanatomical round prosthesis additive to the left. RT makes breast reconstruction difficult, as it gives better results with myocutaneous flaps. FG has a regenerative effect on irradiated tissues. Historically, reconstruction with autologous tissue is preferable to reconstruction with implantation in patients irradiated after mastectomy, as it presents less reoperation ( $16.6 \%$ vs. $37.0 \%$, $\mathrm{p}<0.0001$ ), total complications ( $30.9 \%$ vs. $41.3 \%, \mathrm{p}<0.0001$ ), and reconstructive failure ( $1.6 \%$ vs. $16.8 \%$, p $<0.0001)$. Radiodermite affects more than $90 \%$ of patients treated with RT. The dermis is affected with an increase in fibrosis, reduction in the number of capillaries, and irregular distribution. FG is able to reverse these changes. FG improves the characteristics of irradiated tissue, restores elasticity, and allows breast reconstruction with an implant without a myocutaneous flap.

Keywords: Fat Graft; Radiotherapy; Breast Reconstruction; Breast Implant. 